\title{
The Seventh World Conference on Tobacco and Health
}

The importance of tobacco as a global public health problem is increasing, thanks to the success of the multinational tobacco industry in pushing its lethal wares in the Third World. ${ }^{1}$ It was therefore decided at the last world conference in Tokyo to hold future conferences every two years instead of every four. The seventh conference took place on 1-5 April 1990 in Perth, Western Australia.

The conference was superbly organised by Michael Daube, whom many in Britain will remember as an outstanding director of Action on Smoking and Health (ASH) UK; he is now a senior civil servant in the Health Department of Western Australia, which has initiated much enlightened action on health promotion. About 1000 delegates attended from some 70 countries; bursaries had been provided for many activists from the Third World.

\section{General and political aspects}

The conference was opened by the Prime Minister of Western Australia and attended by ministers of health from Western Australia, Ireland (who is also the current chairman of the Council of Ministers of Health of the European Community), New Zealand, Bangladesh, and Thailand. A speech was read on behalf of the Australian Federal Minister of Health, who was prevented from attending by the formation of a new federal cabinet after the recent election. The Director General of the World Health Organisation, $\mathrm{Dr} \mathrm{H}$ Nakajima, was present, as was the Regional Director of WHO Western Pacific, Dr S T Han. WHO launched its new "Programme on Tobacco or Health" this year and the Western Pacific Region of WHO is actively preparing its own programme. The programme of WHO Europe is well advanced.

The conference showed the increasing purpose and cohesion of the international antitobacco movement and its increasing political successes. For instance, all tobacco advertising is now illegal in Norway, Finland, Italy, Canada, Saudi Arabia, Sudan, French Polynesia, and Singapore. These countries are likely to be followed shortly by France, New Zealand, and Malaysia. Several of these countries have also banned all forms of tobacco promotion and sponsorship. Oral ingestion (snuff dipping) by substances such as "Skoal Bandits" has caused much oral cancer in the United States. This was banned first by Hong Kong but many other countries, including Britain, have followed. The European Community seems likely to follow suit. Many countries have now banned all smoking on domestic air flights.

For the first time representatives of the tobacco industry were formally excluded from the conference. To compensate for this David Simpson, the director of ASH UK, gave a witty address on "What the industry would have said if it were here." His talk consisted entirely of quotations from industry spokesmen, illustrating the ruthlessness, hypocrisy, and sometimes downright silliness of many of their actions and statements. Many at the conference emphasised that we are engaged in a global war, fought against a ruthless industry on behalf of the health of mankind.

The conference heard that the multinationals, using all their financial and political clout to fight back, have had major successes. Using the threat of US trade sanctions, they have broken into the previously protected markets of Taiwan, South Korea, and Japan. They are at present putting enormous pressure on Thailand, which has so far resisted, supported in this by counterpressure by WHO, the international health lobby, and much coordinated non-governmental activity in the United States. Sadly, the multinationals are having considerable success in Japan, where the male smoking rate (even in doctors) is very high, though falling slowly, and intensive promotion is delaying the even slower fall in women. The Japanese government has been very dilatory; its powerful Ministry of Finance even has a committee to promote the use of tobacco, despite steeply rising lung cancer death rates and an increasing, though surprisingly delayed, rise in deaths from ischaemic heart disease.

Kjell Bjartveit from Norway gave a useful account of how the gloomy prognostications of the tobacco and advertising industries on the likely effects of banning tobacco advertising in Norway 15 years ago had not been fulfilled. For instance, the annual increase in the sales turnover of the Norwegian advertising industry was higher in the eight years after the ban than in the eight years before it. The number of employees in the Norwegian tobacco industry dropped by an annual mean of $2.7 \%$ during the 10 years before the ban (owing to increasing mechanisation) and by $2.6 \%$ during the 10 years after it. Total sales of advertisements to Norwegian newspapers increased by $3.9 \%$ in the eight years before the ban and $5.6 \%$ in the eight years after it.

\section{Epidemiology}

The causation of disease by tobacco is now so
Sir John Crofton, 13 Spylaw Bank Road, Colinton,
Edinburgh EH13 0JW. 
well established that most of the conference was concerned with policy and prevention. R Peto (Oxford) and AD Lopez (WHO), ${ }^{1}$ however, produced some grim predictions of the future toll if we do not succeed in controlling the pandemic. Globally, they expect some 3 million deaths a year from smoking related diseases during the $1990 \mathrm{~s}$, probably rising to over 10 million by about 2020 if no effective action is taken. About 500 million of the present population of the world is likely to be killed by tobacco, 250 million of the deaths occurring in people aged 35-69, with an average loss of 20 years of life. Two hundred million of today's children and teenagers will die from tobacco. In China alone they expect 900000 annual smoking related deaths in men by the year 2025 and 50 million in Chinese children and teenagers alive today. The Chinese government has been alerted to this and is actively preparing legislation, so there is some chance that the full tragedy will be averted.

Evidence on the ill effects of passive smoking continues to accumulate-notably on lung cancer and on the higher rates of pneumonia in infants of smoking parents, especially smoking mothers. "Glue ear" in children seems also to be related. There is increasing evidence of a causal relation to ischaemic heart disease. Maternal smoking seems to be associated with cleft palate in certain subgroups who lack adequate compensating enzymes in the placenta.

\section{"Global Link"}

Non-government organisations have been immensely active in the United States. There have been notable successes by the non-smokers' rights movement in achieving legislation in individual states. There has been far more preventive action by the powerful American national heart, lung, and cancer societies than by the equivalent organisations in Britain. The societies have formed a coalition to influence the Federal Government, which has so far taken only minor legislative action. The National Cancer Institute and other governmental agencies are financing ambitious experimental preventive projects costing nearly 200 million dollars. The American Cancer Society, which has done excellent work in stimulating and coordinating anti-tobacco action in Latin America, has just launched an international information network known as Global Link. This will be a computer link with relevant centres throughout the world. It will provide almost instantaneous access to factual data and information on policy. These will be provided both centrally and by feedback from linked centres. For developing countries without the necessary technology communication will be through linked agencies already with their own network of contacts. Those interested should contact the American Cancer Society GLOBALink (1730 Rhode Island Avenue NW, 600 Washington DC 20036, USA) or, in the United Kingdom, the ASH headquarters in London (5-11 Mortimer Street, London W1N 7RH).
Non-smoking hospitals and medical schools

Some states in the United States seem to have been far more effective than Britain in achieving smoke free hospitals. Impressive successes were reported even from psychiatric units and alcohol and drug centres. A national survey in the United States showed that medical schools often lagged behind; only a proportion had a formal policy in writing. It would be interesting to find out how many medical schools in the UK have a "no smoking" policy.

\section{The Third World}

Several workshops, including one on tobacco and the Third World, were held before the start of the main conference. Many relevant contributions were also made during the conference. On behalf of the International Organisation of Consumers Unions (IOCU) Simon Chapman and Wong Wai Leng, with much international help, have compiled an invaluable resource atlas called Tobacco Control in the Third World. ${ }^{2}$ It provides general information and many detailed statistics on individual countries, including economic and social data on their tobacco trades. The atlas also highlights the many gaps in knowledge. Apart from major exporters such as Malawi and Zimbabwe, tobacco growing is evidently not an important economic asset in most developing countries. Indeed, for many there is a net loss: most of their product is consumed internally and much of the profit goes to parent companies in the UK or the United States. Deforestation, resulting from use of wood for tobacco curing, will result in much social and economic loss in the future. In addition to the atlas the International Organisation of Consumers Unions is producing a "pack" for activists, primarily for use in developing countries. ${ }^{3}$

Apart from attempts to prevent the growing epidemic, particularly in women in the Third World (a major target of the multinationals) the enormous problem of mouth cancer resulting from tobacco chewing, especially in the Indian subcontinent, is being increasingly emphasised. Pilot projects have indicated that health education may be effective even among illiterate people, but so far no large scale action has been taken. The conference agreed that this was one of the major challenges for the future.

\section{Children}

Many papers were concerned with children. Some of the more exciting concerned the success of children's "Smoke-buster Clubs" in the UK, now with some 70000 members. There is a national network of similar highly successful clubs in Sweden, as part of that country's "non-smoking generation" project. We also heard of the extent to which, even with the present reduced smoking in Britain, children are still exposed to other people's smoke in their homes or elsewhere. ${ }^{4}$ 


\section{Women}

Women, especially in the Third World, are a major target for the tobacco companies. There was a pre-conference workshop on the subject and many contributions during the conference itself. One of the upshots was the establishment of an International Network on Women and Tobacco, which will function through Global Link. Its first task is to be the gathering of worldwide information on the targeting of women by tobacco companies. Another theme was the necessity of developing specific techniques to help women to stop smoking, especially those living in poverty and social isolation, and the importance of getting women from local communities to take part in devising these programmes.

\section{Medical students}

Professor Paul Fréour of Bordeaux, on behalf of the International Union against Tuberculosis and Lung Disease, gave some preliminary results of the union's global study of the habits, knowledge, and attitudes of medical students regarding the tobacco problem. He reported a wide variation in smoking rates between countries, varying from a very low rate in the UK to a very high one in Japan. Analysis of results from 14 European countries showed some notable gaps in knowledge. Overall, only $29^{\circ}$ o thought smoking a major cause of death from ischaemic heart disease. There was considerable ignorance about prevention, most rating increase in taxation an unimportant measure. In general, students had little confidence in their ability to counsel their patients. Medical schools in many countries clearly need to improve their teaching on this subject.

As many of the sessions were held in parallel one person could not cover everything that was presented. This account is inevitably selective. In addition to the formal sessions much was achieved by informal discussion among activists from all over the world. The momentum will be maintained at the eighth conference, in Buenos Aires in 1992, followed by the ninth in Paris in 1994.

JOHN CROFTON

1 Crofton J. Tobacco and the Third World. Thorax 1990;45:164-9.

2 Chapman S, Wong WL. Tobacco control in the Third World. A resource atlas. Penang, Malaysia: International Organisation of Consumers Unions, 1990.

3 Simpson D. Turning back the tide: tackling the tobacco epidemic. Penang, Malaysia: International Organisation of Consumers Unions, 1990.

4 Michell L. Growing up in smoke. London: Pluto Press, 1990. 